\title{
Solution to element crossword challenge
}

\section{S. Krüger ${ }^{1} \cdot$ B. Hattendorf ${ }^{1}$}

(C) Springer-Verlag GmbH Germany, part of Springer Nature 2020

The winner of the element crossword challenge (published in volume 412 issue 9) is:

Chin-Fen Teo, University of California, San Francisco, CA, USA.

The award entitles the winner to select a Springer book of her choice up to a value of $€ 100,-$.

Our Congratulations!

\section{Solution}

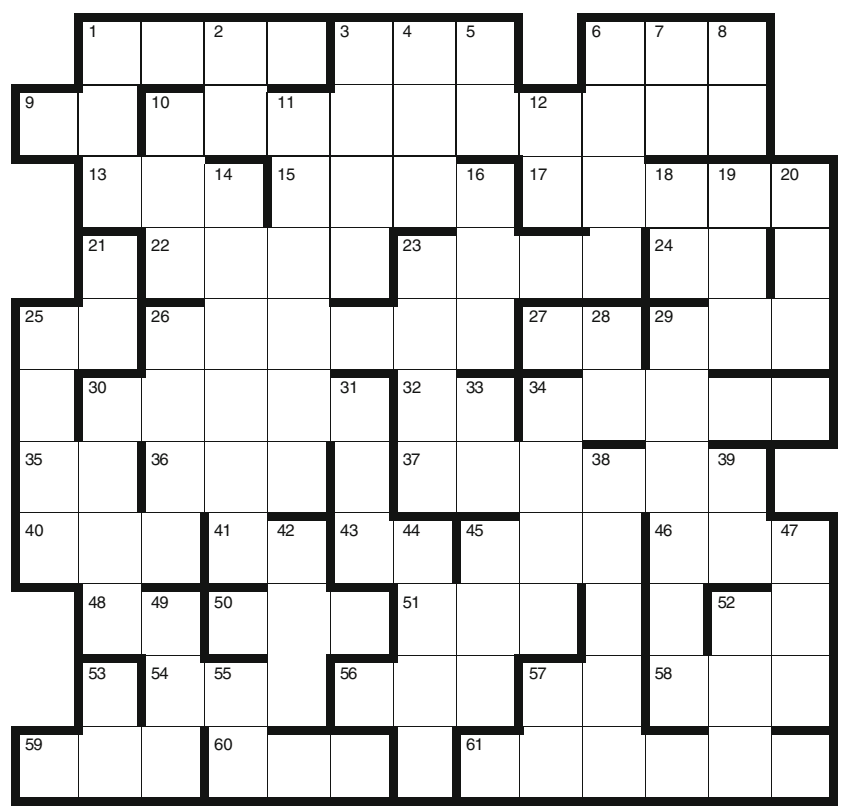

This article is the solution to the Analytical Challenge to be found at https://doi.org/10.1007/s00216-020-02459-1

B. Hattendorf

Zürich, Switzerland

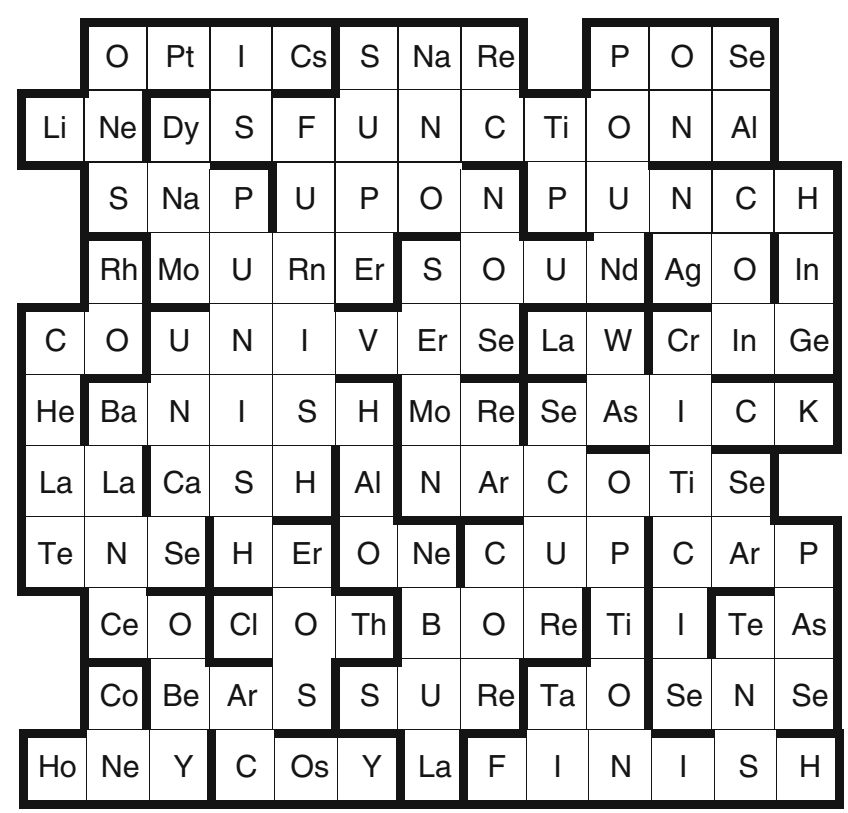

\section{Across}

1 Concerns vision and perception. 3 Noose, frequently found in a drummer's set. 6 Show off to impress me. 9 Not to cross if red. 10 Not a state you want your gadgets in. 13 Released their Power in 1990. Tear. 15 Once .... a time. 17 A drink, a push, a blow. 22 A close one at a funeral. $23 \mathrm{HiFi}$ aims to make it truly realistic. 24 Previously. Add a Big Apple for pain. 25 S(h)ort of a firm. 26 Eternal and mostly ethereal surrounding. 27 Rules from an authority. 29 Possibly the result of a shr(i)ek. 30 Displace as a higher authority. 32 Un-less. 34 Keeping the eyes on the horizon might help if this. $\mathbf{3 5}$ Romantic movie land. 36 Manifests in 19 down. 37 Turn off 58 across. 40 A condition of being tight. A time of speech. 41 Applies to about $50 \%$ of humans. $\mathbf{4 3}$ is greater than this by forty two. $45 \mathrm{~A}$ typical dosage of 52 across. 46 Decorative element in a pond maybe. Complain grumpily. 48 The Boss (in enterprise terms). 50 Limb-wrap. 51 This hole isn't fascinating. $\mathbf{5 2}$ 
Extracts made in various flavors. $\mathbf{5 4}$ Carnivores. A sword shaken. 56 Reliable. 57 Path for life of oriental origin. 58 What 16 down can do. 59 A lure for 54 across. 60 Comfortable. 61 What else could it be (here at the end)?

\section{Down}

1 seen more than once. 2 Was, then. 3 Joins with market, man or vision. 4 Popular dimension of the tiniest things. 5 Short for leisure, note or bill. 6 Imperial representation of gravity? British trade unit. 7 Anti off. 8 Isolation at its best. 10 Electron mover 11 Fleecing? No! Do this to your home! 12 Generously given, thankfully accepted! $\mathbf{1 4}$ ment to be absent when abiding the 27 across. 16 Airborne's detector. 18 Not for horse racing, not for a good mood. 19 A possible manifestation of 6 down. Not a note. 20 Keeps your door in place. 21 Resembles density. 23 You may want to hear it from a priest not your neighbor. 25 Complex by multiple means. 26 Anti- box? 28 Representation of time gone by. 29 To give a rather negative feedback. 30 Good to have for your working life after your work-life. 31 A sort of fuzziness seen around a saint's head. 33 Back. 34 Your password should be this. 38 Left? Right? A choice. 39 What a grill ideally does to the outside only. 42 Greek god of arrows. Love it. 44 Interstellar "fog". 45 Center! Carbonaceous metal-rich mineral?? 47 Over. 49 Do what you are told! $\mathbf{5 2}$ Decades, in years. $\mathbf{5 3}$ Ice creams crispy companion. 55 Structural element in wider spans. Almost central element of monarchies. 57 A mouthful in Southeast Asia.

Publisher's note Springer Nature remains neutral with regard to jurisdictional claims in published maps and institutional affiliations. 